\title{
PEMANFAATAN CITRA LANDSAT 8 UNTUK MEMETAKAN PERSEBARAN LAMUN DI WILAYAH PESISIR PULAU BATAM
}

\author{
Oleh \\ Dewi Puspa Sari, Muhammad Zainuddin Lubis \\ Jurusan Teknik informatika konsentrasi Teknik Geomatika, Politeknik Negeri Batam \\ Email : zainuddinlubis@polibatam.ac.id \\ Received February 2017, Accepted March 2017
}

\begin{abstract}
ABSTRAK
Satelit landsat 8 memberikan informasi (citra/gambar/foto peta) secara gratis yang bisa di unduh dari website resmi. Peneliti menggunakan beberapa software seperti ENVI, ER MAPPER, dan ArcGIS yang merupakan software untuk pengolahan citra. Analisis Lyzenga digunakan untuk pengkoreksian kolom perairan agar kenampakan objek pada sensor satelit menjadi lebih baik. Penelitian dilakukan pada bulan Agustus 2016 dengan menggunakan metode Lyzenga, koreksi citra, serta klasifikasi. Hasil penelitian ini menunjukan adanya hubungan dari sebaran vertikal telah didapatkan bahwa stasiun yang paling lemah terletak pada daerah piayu, dari semua stasiun kecerahan tertinggi berada pada daerah Nongsa, DO tertinggi di daerah Piayu dan suhu tertinggi di daerah Sekupang. Hubungan korelasinya dari semua stasiun memiliki hubungan yang negatif/ lemah. Namun dari semua stasiun yang paling kuat hubungannya terletak di daerah nongsa. Hal ini menyebabkan tidak ditemukan lamun yang hidup secara monospesifik dan daerah tersebut belum mengalamin ganguan ekologis secara nyata. Karakteristik habitat, struktur komunitas, ancaman dan rencana sebaran lamun ikut dibahas.
\end{abstract}

Kata kunci : Citra landsat 8, Habitat, Lamun, Lyzenga.

\section{ABSTRACT}

Landsat 8 satellite provides information (image / picture / photo map) operating free which can be downloaded from the official website. Researcher using some software such as ENVI, ER Mapper, and ArcGIS which is software for image processing review. Lyzenga analysis is used to review the correction of water column so that the appearance of the object in Satellite sensors for the better. The study was conducted during the month of August 2016 using method with lyzenga, proofreading imagery, as well as classification. Results showed their relations singer of vertical distribution has found that very weak stations located on the area is Piayu, of all on stations are the highest brightness area is Nongsa, the highest of DO values in the region is Piayu and the highest temperature in the area is Sekupang. From the correlation relationship all stations have negative relationships / weak. However of the pale strong all stations located in the area to do is Nongsa. This cause is not found in monospecific seagrass life and the area has not happened in real ecological disturbances. Characteristics habitat, community structure, threats and seagrass distribution plan participate discussed.

Keywords: Habitat, Landsat 8, Lyzenga, Seagrass. 


\section{PENDAHULUAN}

Ekositem laut di Indonesia mempunyai potensi besar untuk menyerap $\mathrm{CO}_{2}$ sebagai gas utama yang penyebab pemanasan global yang nantinya berhubungan dengan terjadinya perubahan iklim. Salah satu sumber daya laut yang cukup potensial untuk dapat dimanfaatkan sebagai penyerap gas $\mathrm{CO}_{2}$ adalah padang lamun yang secara ekologis padang lamun mempunyai beberapa fungsi penting di wilayah pesisir karena padang lamun merupakan satu-satunya tumbuhan berbunga yang ada di laut yang berperan penting dalam melakukan penyerapan karbon di laut juga melalui fotosintesis (Kawaroe, 2005).

Lamun memiliki peran memberikan tempat perlindungan dan tempat menempel bagi hewan dan tumbuhan (algae). Selain itu sebagai tempat makanan dari berbagai jenis ikan herbivora dan ikan karang. Fungsi dan peran lamun, bergantung pada jumlah helai daun, panjang, lebar, serta biomassa total semua tergantung kondisi tempat. Hampir semua substrat/sedimen dapat ditumbuhi lamun, mulai dari berlumpur hingga berbatu. Namun sering ditemukan di berlumpur-pasir. Substrat menentukan kestabilan lamun agar tidak terbawa arus dan gelombang. Jika substrat menipis maka kehidupan lamun tidak stabil, sebaliknya jika substrat tebal maka lamun tumbuh subur, yaitu berdaun panjang dan rimbun. Perbedaan komposisi jenis substrat dan komposisi jenis lamun dapat mempengaruhi adanya perbedaan kesuburan dan pertumbuhan pada lamun. Karena perbedaan komposisi ukuran butiran pasir menyebabkan perbedaan nutrisi bagi pertumbuhan lamun dan dekomposisi dan meneralisasi terjadi dalam substrat (Pragunanti, 2016).

Lamun atau seagrass merupakan tumbuhan berbunga yang sepenuhnya menyesuaikan diri dengan hidup terbenam dalam laut. Tumbuhan ini terdiri dari rhizome (rimpang), daun, dan akar. Rhizome merupakan batang yang terbenam dan merayam secara mendatar, serta berbuku-buku. Pada buku-buku tersebut tumbuh batang pendek yang tegak keatas, berdaun dan berbunga, serta tumbuh akar. Rhizome dan akar inilah yang berfungsi untuk menahan hempasan ombak dan arus. Lamun sebagian besar berumah dua, yaitu dalam satu tumbuhan hanya ada satu bunga jantan saja atau satu bunga betina saja. Sistem pembiakan bersifat khas karena mampu melakukan penyerbukan di dalam air (hydrophilous pollination) dan buahnya juga terbenam di dalam air (Azkab, 2006).

Dalam perairan yang sangat jernih, beberapa jenis lamun bahkan di temukan tumbuh sampai kedalaman 8-15 $\mathrm{m}$ dan $40 \mathrm{~m}$. Bila dibandingkan dengan padang lamun yang tumbuh di sedimen karbonat yang berasal dari patahan terumbu karang, maka padang lamun yang tumbuh di sedimen yang berasal dari daratan lebih dipengaruhi oleh faktor run off daratan yang berkaitan dengan kekeruhan, suplai nutrient pada musim hujan, serta fluktuasi salinitas (Dahuri, 2003).

Menurut Kuriandewa (2009), Indonesia mempunyai luas padang lamun sekitar $30.000 \mathrm{Km} 2$. Padang lamun yang begitu luas memungkinkan banyaknya biota yang hidup berasosiasi dengan lamun seperti alga, moluska, krustasea, enchinodermata, mamalia dan ikan. Padang lamun banyak di huni oleh ikan-ikan, baik tinggal menetap, sementara maupun mengunjungi untuk mencari makan atau melindungi diri dari pemangsa. Peranan lamun begitu besar namun sering kali ekosistem ini kurang mendapat perhatian. Menurut Warastri (2009), kondisi ekosistem padang lamun di perairan Indonesia mengalami kerusakan sekitar $30-40 \%$. 
Kepulauan Riau merupakan daerah provinsi baru yang sedang berkembang dalam berbagai sektor, baik sektor ekonomi maupun sosial. Salah satu perkembangan dalam sektor ekonomi adanya reklamasi daerah pesisir. Hal ini memungkinkan akan menjadi salah satu faktor penyebab kerusakan alam di perairan Kepulauan Riau. Menurut informasi yang didapat kegiatan penambangan pasir laut telah berlangsung sejak tahun 1970, yakni wilayah yang berbatasan langsung dengan Singapura. Kegiatan tersebut telah mengeruk jutaan ton pasir setiap hari dan mengakibatkan kerusakan ekosistem pesisir pantai yang cukup parah.

Penambangan pasir laut juga mengancam keberadaan sejumlah pulau kecil karena dapat menenggelamkannya, misalnya kasus Pulau Nipah. Tenggelamnya pulau-pulau kecil tersebut menimbulkan kerugian besar bagi Indonesia, karena dengan perubahan pada kondisi geografis pantai akan berdampak pada penentuan batas maritim dengan Singapura di kemudian hari (Yono, 2009).

Teknik penginderaan jauh dengan memanfaatkan citra satelit Landsat 8 dapat memberikan banyak keuntungan untuk digunakan dalam pemetaan lamun di pesisir Batam.untuk mengetahui sebaran lamun, berdasarkan latar belakang diatas peneliti melakukan penelitian berjudul pemanfaatan citra landsat 8 untuk memetakan persebaran lamun di wilayah pesisir Batam.

\section{MATERI DAN METODE}

\section{Lokasi Penelitian}

Kegiatan penelitian ini dilakukan di kota Batam 1.05'Lintang Utara dan 104。 02'Bujur Timur dengan waktu perekaman dimulai dari tanggal 21 Agustus 2016, dan waktu pengolahan 5 bulan (Agustus - Desember 2016).

\section{Parameter Oseanografi}

Parameter oseanografi yang diukur adalah DO, Suhu dan Kecerahan karena ketiga parameter fisika ini merupakan faktor yang paling berpengaruh terhadap persebaran lamun. Pengukuran suhu dan DO dengan cara memasukan alatnya kedalam air laut maka akan terlihat berapa rekaman suhu dan DO nya, sedangkan kecerahan menggunakan sebuah kaset CD, Tali, Pemberat. Dimana semua alatnya di ikat kemudian dicelupkan ke dalam air laut seberapa dalam kecerahan yang diketauhi dan berapa meter kedalaman yang didapat.

\section{Koreksi Radiometrik}

Koreksi radiometrik merupakan tahapan awal pengolahan data sebelum analisis dilakukan, misalanya untuk identifikasi persebaran lamun.Koreksi radiometrik juga merupakan teknik perbaikan citra satelit untuk menghilangkan efek atmosferik yang mengakibatkan kenampakan bumi tidak selalu tajam. Proses koreksi radiometrik mencakup koreksi efek-efek yang berhubungan dengan sensor untuk meningkatkan kontras (enhancement) setiap piksel (picture element) dari citra, sehingga objek yang terekam mudah diinterpretasikan atau dianalisis untuk menghasilkan data/informasi yang benar sesuai dengan keadaan lapangan (Supriatna, 2002).

\section{Koreksi Geometrik}

Koreksi geometrik merupakan proses memposisikan citra sehingga cocok dengan koordinat peta dunia yang sesungguhnya. Proses ini akan ditampilkan ketidak tepatan dalam proses memasukan koordinat dengan letak tidak sesungguhnya. Pada dasarnya kesalahan tersebut masih dapat diterima jika masih memenuhi kaidah 
kartografi. Jumlah titik yang dicatat koordinatnya minimal empat titik. Titik-titik tersebut di anjurkan menyebar terutama pada daerah yang bertopografi berbukit sampai bergunung. Proses dalam koreksi geometrik bertujuan untuk mengembalikan posisi setiap piksel citra satelit asli sehingga mengikuti citra terkoreksi. Hasil dari proses tersebut akan menghasilkan citra yang mempunyai koordinat sesuai dengan peta topografi (Supriatna, 2002).

\section{Metode Lyzenga}

Dimana metode ini digunakan untuk memisahkan region daratan dan lautan. Agar pengolahan hanya di proses pada area lautan saja. Algoritma lyzenga yang digunakan adalah (Jaelani et al., 2015), dan diagram alir penelitian dapat dilihar pada Gambar 2 dibawah ini.

$$
Y=\ln (L i)-\left[\left(\frac{k i}{k j}\right) \times \operatorname{In}(L j)\right]
$$

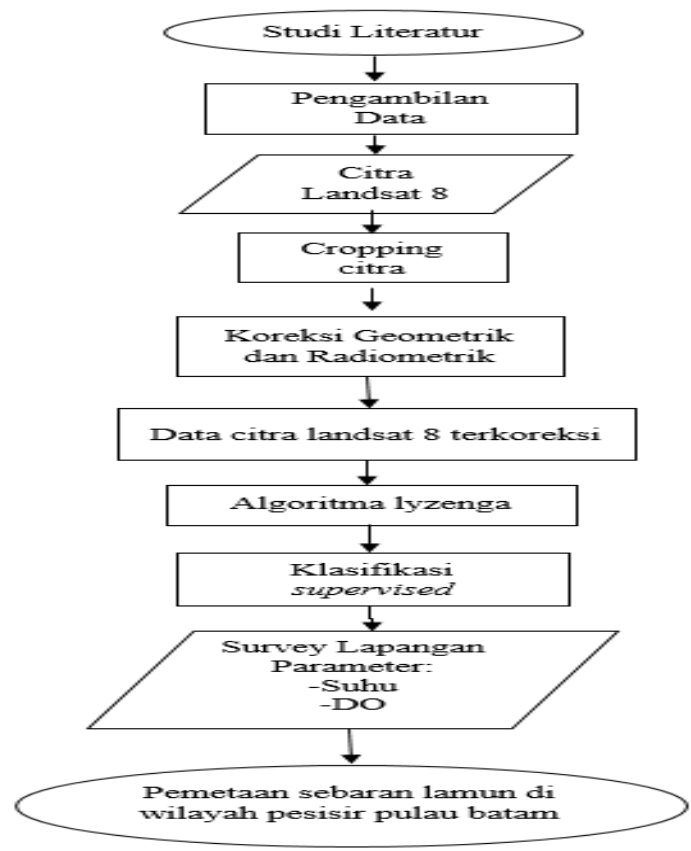

Gambar 2. Diagram alir penelitian

\section{HASIL DAN PEMBAHASAN}

Hasil uji kebenaran dari masing-masing kelas pada sistem cek lapangan untuk menentukan persebaran lamun menggunakan parameter oseanografi untuk mengetahui keadaan fisika pada lamun tersebut seperti suhu, kecerahan, dan DO (Liu et al., 2013). Selain alat tersebut pada penelitian menggunakan GPS yang digunakan sebagai petunjuk lokasi keberadaan lamun. Sebaran suhu dan Dissolved Oxygen (DO) dengan melihat posisi x dan y dapat dilihat pada Gambar 3. 

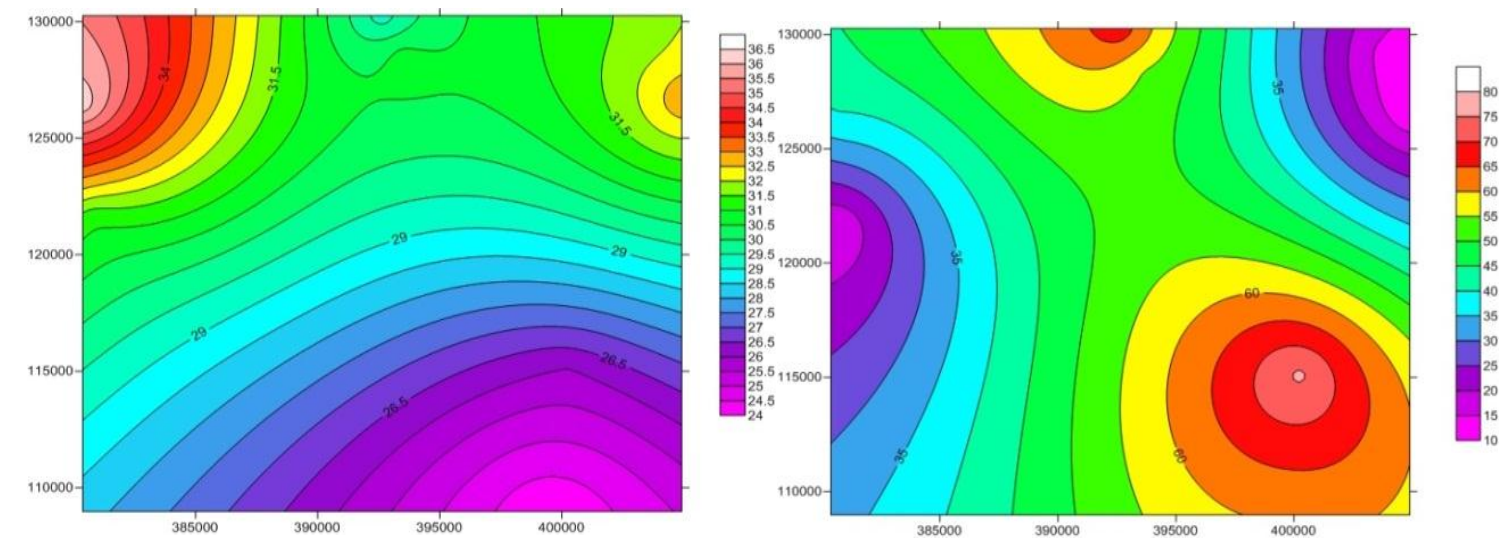

Gambar 3. Sebaran suhu (atas) dan dissolved Oxygen (DO)

Berdasarkan hubungan antara DO dan Suhu dapat ditafsirkan sebagai hubungan antara suhu dan DO memiliki nilai 0,5941 atau $59,41 \%$ dan 0,8502 atau $85,02 \%$ yang dapat dikategorikan memiliki hubungan yang sedang, tetapi karena nilai $\mathrm{R}$ adalah 0 maka hasil analisa secara statistik nilai suhu dan DO tidak memiliki hubungan (Gambar 4).

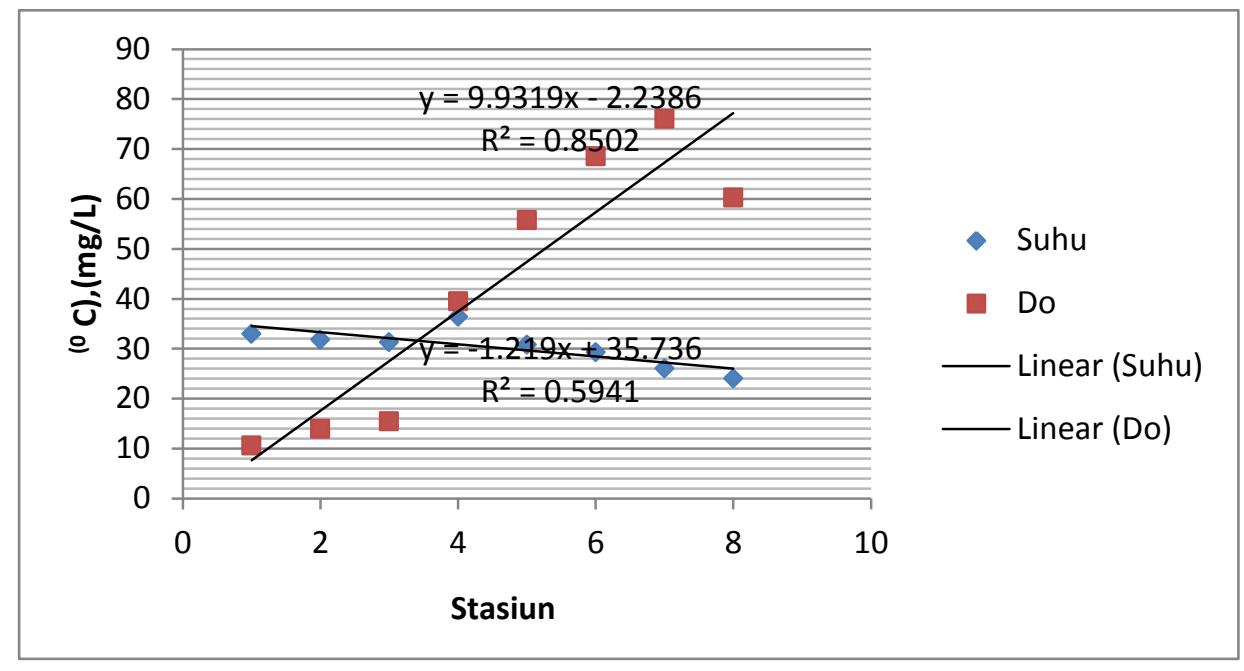

Gambar 4. Hubungan kecerahan dan DO

Hasil sebaran lamun yang ada di wilayah Pulau Batam menunjukkan sebaran lamun hanya ada di daerah Nongsa, Piayu Laut, Bengkong, dan Sekupang. Beberapa faktor alam yang menjadi penentu keberadaan lamun yaitu perubahan iklim dan bencana alam. Hal ini berdampak kepada semua ekosistem yaang ada di muka bumi khususnya lamun yang memiliki toleransi suhu optimal berkisar antara 24-36 0C di perairan. Sebaran lamun di Pulau Batam yang diketahui dari parameter oseanografi dimana daerah yang paling rendah pertumbuhan lamunnya di daerah Piayu sedangkan yang masih banyak lamunnya berada di daerah Bengkong, hal ini dapat dilihat pada Gambar 4 dan 5. 

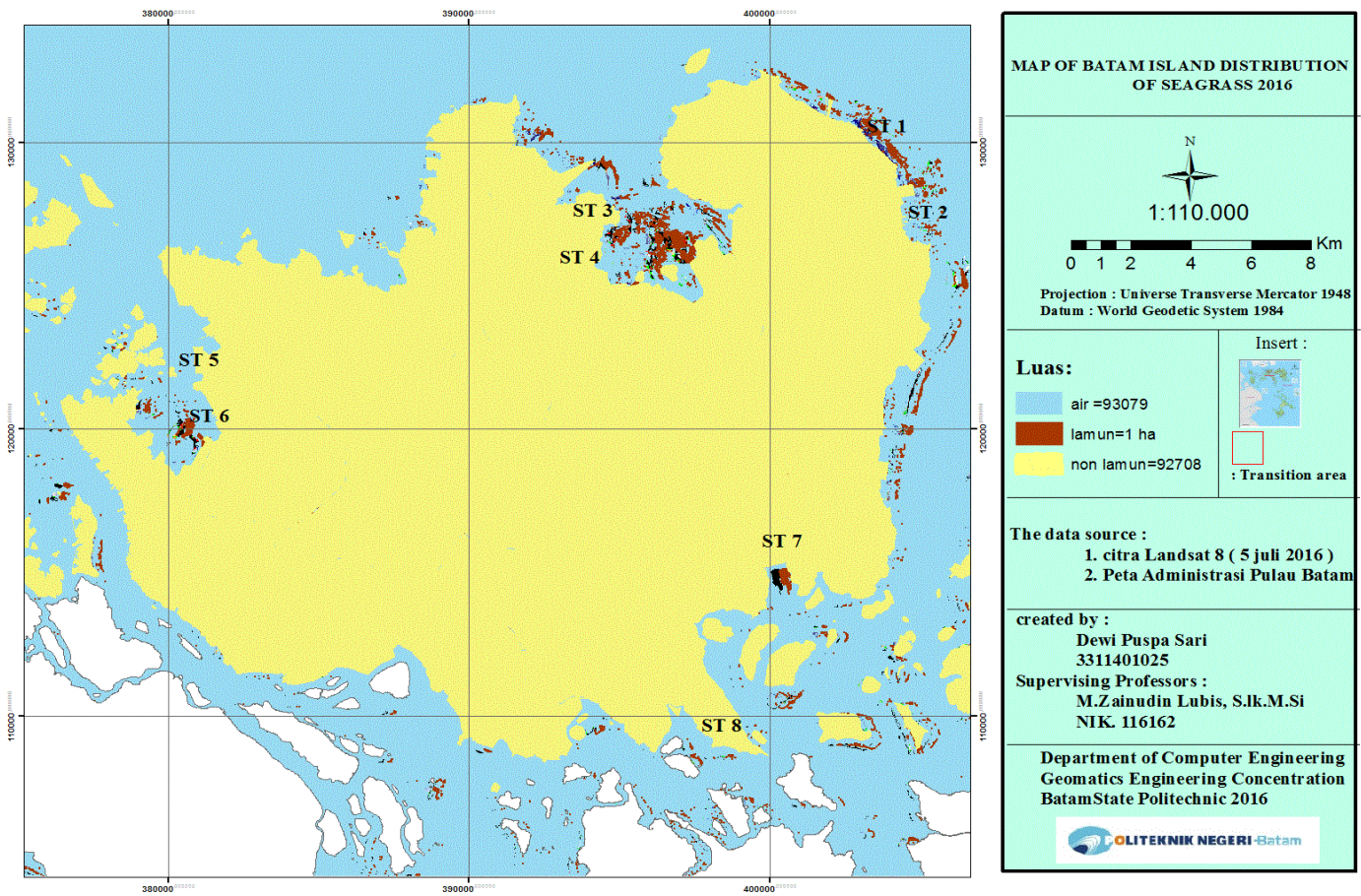

Gambar 5. Peta Pesebaran Lamun

Sedangkan penyebaran lamun mulai dari pantai ke arah tubir umumnya berkesinambungan, perbedaan yang terdapat biasanya hanya pada komposisi jenisnya dan luas tutupannya (Dahuri et al., 2001). Hal ini diduga karena kondisi lingkungan seperti kandungan nutrient pada substrat yang tidak merata sehingga lamun hanya tumbuh pada titik tertentu. Selain ketersediaan nutrient yang cukup juga dapat dilihat arah dan kecepatan arus mempengaruhi keberadaan beberapa jenis lamun, karena ada jenis lamun yang dapat beradaptasi dengan kondisi arus besar dan ada yang tidak.

Secarah harfiah Teluk Bakau merupakan daerah yang terletak di Pulau Bintan, Kepulauan Riau dan Pulau Bintan merupakan daerah ibu kota Provinsi Kepulauan Riau. Daerah ini merupakan daerah yang baru berkembang setelah lepas dari Riau kurun lebih 2 periode. Infrastruktur yang berkembang pada Pulau Bintan relatif masih baru. Menurut Yono (2009) dahulu Pulau Bintan merupakan Pulau yang di eksploitasi hasil alamnya, salah satunya adalah pasir dan bauksit. Kegiatan ini telah berlangsung sejak tahun 1970. Kegiatan tersebut telah mengeruk jutaan ton pasir setiap hari dan telah mengakibatkan kerusakan ekosistem pesisir pantai yang cukup parah.

\section{KESIMPULAN}

Berdasarkan hasil yang di dapat diketahui bahwa kondisi parameter oseanografi terhadap sebaran lamun menunjukkan adanya daerah yang sebaran lamunnya mulai menurun/berkurang berada di daerah Piayu Laut. Pada peta sebaran lamun pada kondisi perairan yang ada di Pulau Batam tidak memberikan pengaruh yang besar terhadap sebaran lamun. Hasil analisis citra menggunakan citra landsat 8 menunjukan kondisi padang lamun yang ada di Pulau Batam $\pm 80 \%$ masih ada lamun di setiap daerah sedangkan $\pm 30 \%$ sebaran lamun di setiap daerah sudah tidak ada lagi. 


\section{DAFTAR PUSTAKA}

Azkab MH. 2006. Ada apa dengan lamun. Majalah Semi Polpuler Oseana 31(3): 4555

Dahuri R, Rais J, Ginting SP \& Sitepu MJ. 2001. Pengelolaan sumberdaya wilayah pesisir dan lautan secara terpadu. Pradnya Paramita. Jakarta. Xxiv +305 hml.

Dahuri R. 2003. Keanekaragaman hayati laut, aset pembangunan berkelajutan Indonesia. PT. Gramedia Pustaka Utama. Jakarta. xxxiii + 412 hml.

Jaelani Lalu M, Laili Nurahida, Marini Yennie. 2015. Pengaruh algoritma lyzenga dalam pemetaan terumbu karang menggunakan worldview-2, studi kasus: perairan PLTU Paiton Probolinggo. jurusan teknik geomatika, fakultas teknik sipil dan perencanaan. Institut Teknologi Sepuluh Nopember.

Kawaroe, Mujizat. 2005. Pemakaian marine carbon sink sebagai potensi kelautan yang belum populer. Sekolah pasca sarjana. Institute Pertanian Bogor.

Kuriandewa, T. E. 2009. Tinjauan tentang lamun di Indonesia. Lokakarya Nasional I Pengelolaan Ekosistem Lamun. Jakarta, Sheraton Media.

Liu, J. M., Jiao, L., Lin, L. P., Cui, M. L., Wang, X. X., Zhang, L. H., ... \& Jiang, S. L. 2013. Non-aggregation based label free colorimetric sensor for the detection of Cu $2+$ based on catalyzing etching of gold nanorods by dissolve oxygen. Talanta, $117,425-430$.

Pragunanti, Turissa. 2016. Pemanfaatan citra landsat 8 untuk memetakan kondisi tutupan padang lamun hubunganya dengan tekstur sedimen dipulau pajenekang kabupaten pangkep. Universitas Hasanuddin Makassar.

Supriatna, Wahyu. Sukartono. 2002. Teknik perbaikan data digital (koreksi dan penajaman) citra satelit. Buletin Teknik Pertanian. 7(1).

Warastri, Sundari Weaning. 2009. Penggunaan Data Citra Pengindreaan Jarak Jauh untuk Mengetahui Sebaran Biomassa Lamun di Gugus Pulau Pari, Kepulauan Seribu. Jakarta. [Skripsi]. Intitut Pertanian Bogor;Bogor.

Yono. 2009. Bumi Bintan Hancur Karena Tambang Pasir dan Bauksit. Detikriau.net diakses pada tanggal 19/02/2017 [02.45]. 